\title{
Stereovision for the determination of fireline intensity in vegetation fire
}

\author{
L. Rossi, T. Molinier, P. Santoni, T. Barboni \& F. Morandini \\ UMR CNRS 6134, University of Corsica, Corsica
}

\begin{abstract}
Fireline intensity is one of the most relevant quantities in forest fire science. It helps to evaluate the effects of fuel treatment on fire behaviour, to establish limits for prescribed burning. It is also used as a quantitative basis to support fire suppression activities. However, its measurement at field scale for actual fire remains a challenge. Hence, it has been poorly used as a key quantity to test the new generation of models of fire spread that have been developed these last ten years. An inverse method to obtain fireline intensity is through the observation of the flame length. This geometrical information is measured using a stereovision system placed in the lateral position relative to the direction of the fire spread. Algorithms were developed in order to automatically segment the fire area of the images and estimate the 3D coordinates of salient fire points and then the flame length. The three dimensions of the information permit to obtain the flame length with metric measures. In the present work, we directly measure the fireline intensity at laboratory scale by oxygen consumption calorimetry. The results are then used to establish a relationship between fireline intensity and flame length obtained by the stereovision system.
\end{abstract}

Keywords: stereovision, 3D coordinates, fireline intensity, flame length, oxygen consumption calorimetry.

\section{Introduction}

Fires devastate regularly forests and shrublands as well as populated areas all over the world. Foresters and fire fighters are faced with problems such as the management of wildland/urban interfaces, the establishment of safety zones and suppression strategies. An important concept helpful in fire mitigation and fight is to scale fires in function of their potential threat. This scale is based on the 
measure of the fireline intensity of fires, but such measure remains a challenge. The concept of fireline intensity was introduced by Byram [1] in the 1950s. It is the rate of heat released per unit time per unit length by the active flaming zone of the fire front. It is given by:

$$
I_{B}=H w r
$$

where $I_{B}(\mathrm{~kW} / \mathrm{m})$ is the fireline intensity, $H(\mathrm{~kJ} / \mathrm{kg})$ is the heat yield of the fuel, $w$ $\left(\mathrm{kg} / \mathrm{m}^{2}\right)$ is the weight of fuel consumed in the active flame front and $r(\mathrm{~m} / \mathrm{s})$ is the rate of spread of the fire. The fireline intensity is a widely used measure in forest fire applications: it helps to evaluate the effects of fuel treatment on fire behaviour [2], to establish limits for prescribed burning [3], to assess fire impacts on ecosystems [4]. It is also used as an indicator for the classification of fires in terms of risk [1] or as a quantitative basis to support fire suppression activities [5]. The measure of the fireline intensity according to Eqn (1) is extremely difficult because it requires determining the fuel consumption in the fire front. An alternative method consists in measuring the geometrical properties of the flame and use a correlation to derive the fire intensity. The flame length is defined as the distance from the base of the flame to the highest point of the flame [6]. For instance Byram [1] proposed the following relationships between flame length and intensity:

$$
L_{B}=0.0775 I_{B}^{0.46} \Leftrightarrow I_{B}=259 L_{B}^{2.17}
$$

Several authors have proposed other correlations to estimate fireline intensity from flame length measurements [7-10]. These laws exhibit differences in the coefficients and the corresponding curves are strongly different. These differences may be attributed to the varying experimental conditions of the observed fires, to the difficulty in measuring the flame length and to the uncertainty in measuring the fireline intensity. For more than two decades, visual and infrared cameras have been used as complementary metrological instruments in fire spreading experiments $[11,12]$. The image processes used only $2 \mathrm{D}$ information and were not able to provide metric measurements unless calibrated objects were present in the image.

The aim of this paper is to address both major sources of uncertainty. Firstly the use of a stereovision system in order to determine the flame properties is proposed. The stereovision system is built using a visual spectrum pre-calibrated stereo camera without the need of position markers for deriving scale and orthogonality from images. No a priori knowledge is necessary in order to use the proposed approach. Then, we present a methodology to measure the fireline intensity based on oxygen consumption calorimetry principle. Thanks to both methods to measure flame length and fireline intensity, a new relationship between these quantities is obtained at laboratory scale. It is then compared with the existing correlations found in the literature. 


\section{Stereoscopic methodology}

A stereo vision system is composed by two cameras, fig. 1. Each camera, considered as pinhole, is defined by its optical center $O_{l}$ (for the left one), its optical axis $\left(O_{l} z_{l}\right)$ perpendicular to the image plane and its focal length. Each camera has intrinsic parameters (pixel coordinates of the projection center, vertical and horizontal distortions) and extrinsic parameters (characterizing the position and orientation of the camera relative to an object; three rotations and three translations parameters). Let $P$ be a point in a 3D space; $P_{l}$ and $P_{r}$ are respectively the image of $P$ in the left and right image planes. The line $\left(e_{l} P_{l}\right)$ is the epipolar line representing the set of left image points corresponding $P_{l}[13-$ $16]$.

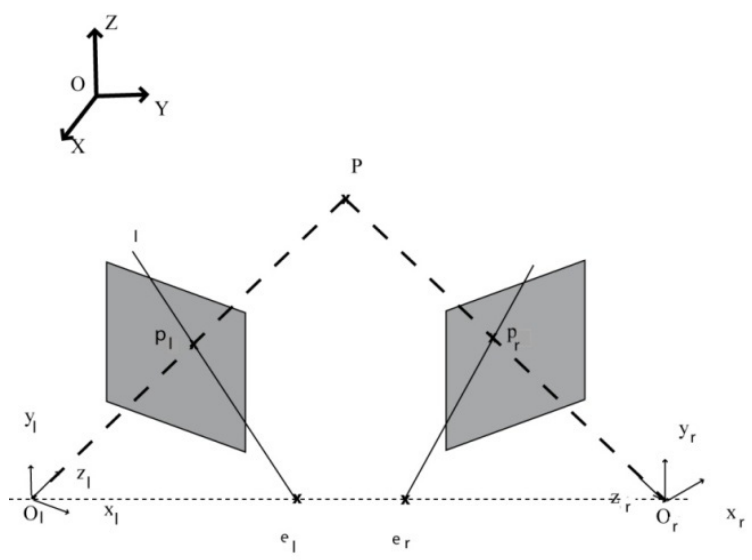

Figure 1: General case of a stereo vision system.

The fundamental matrix $F$ is the algebraic representation of the epipolar geometry:

$$
\left(e_{l} P_{l}\right)=F P_{r}
$$

$F$ incorporates intrinsic and extrinsic parameters of the cameras. The fundamental matrix is computed by calibration with a frame or right-left correspondences. The 3D position is depicted by a stereo disparity defined by the difference between the projected points in two stereo images. A 2D-search is thus needed in order to find corresponding points in both images along the epipolar lines. With the fundamental matrix, it is possible to do an image rectification. The rectification procedure transforms each image plane such that pairs of conjugate epipolar lines become collinear and parallel to one of the image axes. The rectified images can be thought of as acquired by a new stereo rig, obtained by rotating the original cameras. With rectification, computing stereo correspondences is reduced to a 1-D search problem along the horizontal raster lines of the rectified images. Once the corresponding features are extracted, a triangulation technique is used to compute their $3 \mathrm{D}$ coordinates. A 
line $l$ is passed through the point in the left image and the left optical center $C_{l}$ and a line $r$ is passed through the corresponding point in the right image and the right optical center $C_{r}$. A mid-point method finds the point which lies exactly at the middle of the shortest line segment joining the two projection lines. This point represents the 3D coordinate of the corresponding pixels, fig. 2 .

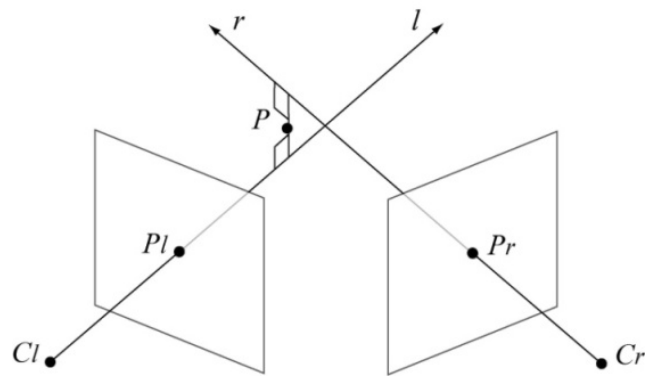

Figure 2: $\quad$ Triangulation method.

Feature points are salient points of the image. The Harris detector is the most commonly used operator for corner point extraction. It is based on local autocorrelation of the signal $[17,18]$. This operator measures local changes of gray levels. In some cases, regions of interest detection is performed in a given color system prior to salient points extraction. This segmentation permits the extraction of connected parts of an image based on color criteria [19]. Then follows a contour detection carried out for example by using the Harris edge detector and the Corner detector based on global and local curvature properties [19-21]. Based on global Feature points are then searched along the contours. When feature points are located in the right and left images, a matching algorithm is used in order to find corresponding points in the two images. Matching algorithms can be classified as correlation-based and feature-based methods [17]. In correlation-based methods, used in this work, the elements to match are image windows of fixed size, and the similarity criterion is a measure of the correlation between windows in the two stereo images.

\section{Experiments}

\subsection{Experimental procedure to measure the flame characteristics}

The measurement of the flame length was carried out using a stereovision system placed in lateral position relative to the direction of the fire spread (circled system in fig. 3).A Point Grey pre-calibrated Bumblebee ${ }^{\circledR}$ XB3 camera was used $[22,23]$. This camera is a trinocular multi-baseline stereo camera with an extended baseline of $24 \mathrm{~cm}$. It has a focal length of $3.8 \mathrm{~mm}$ with $66^{\circ} \mathrm{HFOV}$. The image sensor is a $1 / 3^{\prime \prime}$ Sony ICX445AQ CCD. This system is pre-calibrated for stereo processing. The image resolution is $1280 \times 960$ with a frame rate of 16 FPS. 


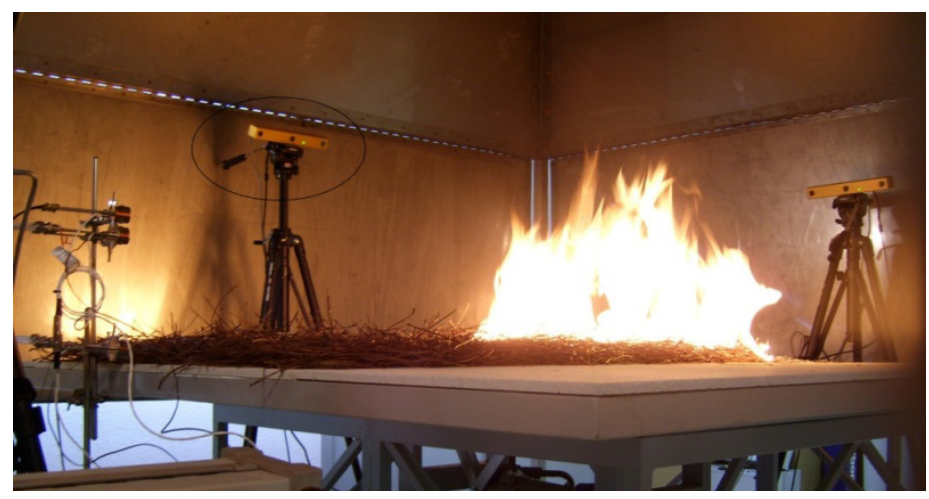

Figure 3: $\quad$ Experimental vision device.

Image acquisition was developed using $\mathrm{C}++$ with Point Grey Triclops SDK. This system permits the simultaneous acquisition of a pair of images of the scene. The captured images are stored for further processing using algorithms developed with Matlab ${ }^{\circledR}$. The experiments were carried out with a frame rate of $0.25 \mathrm{~Hz}$. Only the images within the steady phase were treated. The threedimensional points of fire were obtained from stereoscopic images. The steps involved in this approach are [24]:

1- Segmentation of fire regions; Ko's segmentation algorithm is used in this work [25],

2- Extraction of salient features points,

3- Features selection refinement using a normalized cross-correlation matching strategy,

4- Computation of three-dimensional fire points using stereo correspondence.

Figure 4 shows the fire area segmented in the image with the matched points detected on the entire contour of the fire. Figure 5 shows the 3D points of the fire obtained from the corresponding points marked in Figure 4. The X-axis corresponds to the depth of the fire front; the Y-axis corresponds to its height, and the $\mathrm{Z}$-axis to its width. The reference frame has its origin in the left image center point of the XB3 camera. In order to visualize the correspondence between the 2D and the 3D information, four points are numbered in fig. 4 and fig. 5. With 2D data, it is impossible to distinguish points that are on the ground from points located above whereas it is possible with $3 \mathrm{D}$ information. For example, the Y coordinate of the point number 1 shows that this point is not on the ground.

The length of the flame is defined as the distance between the ground and the highest $3 \mathrm{D}$ points. It is thus necessary to estimate the position of the ground. A method was developed in order to obtain automatically the ground even if the plane is inclined. The lowest 3D points of the back part of the smoldering fire 


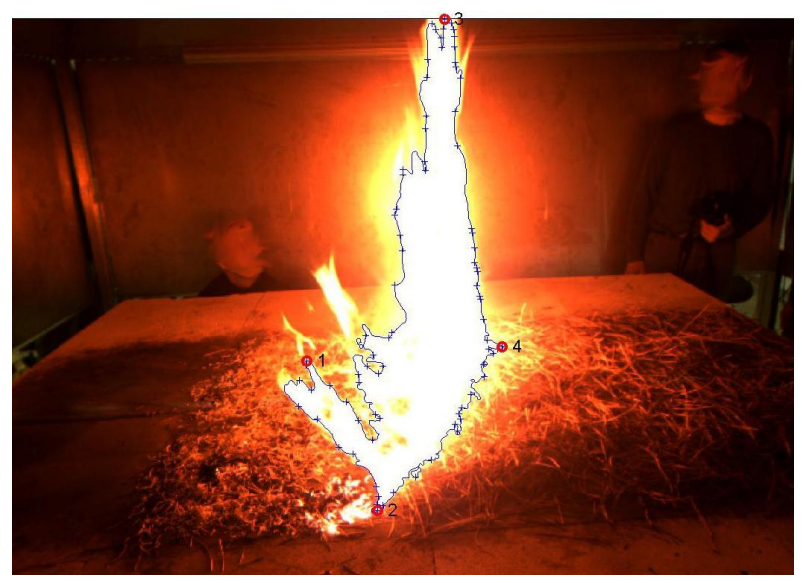

Figure 4: Segmentation of the fire region.
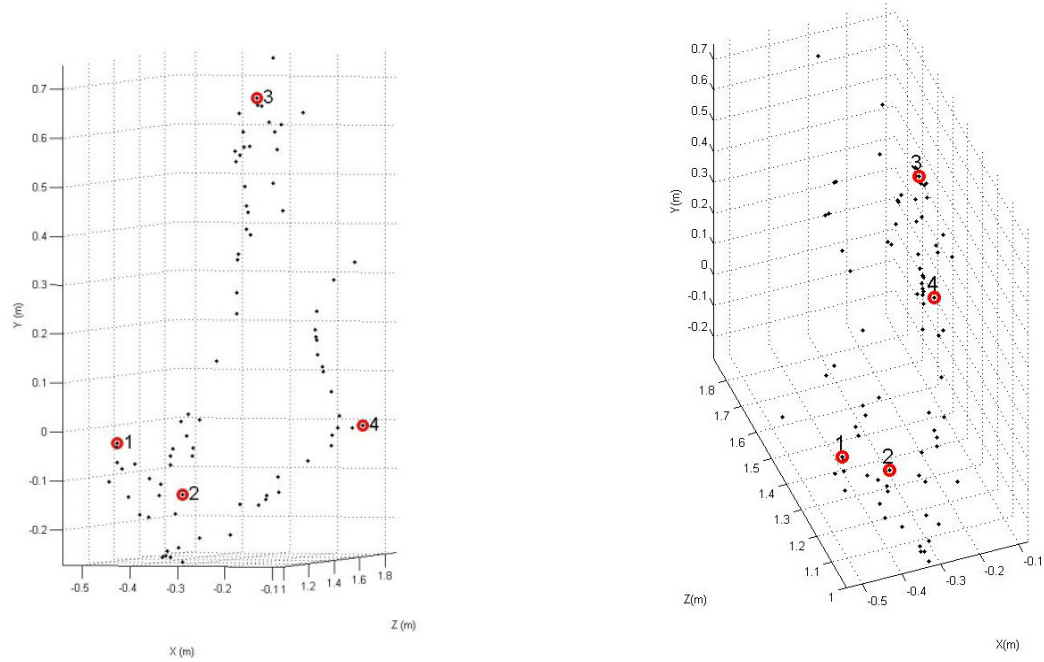

Figure 5: $3 \mathrm{D}$ fire points.

front are identified for all the images and a plane is estimated from these points using a least square method. Then, through homography, the coordinates of the 3D points are selected to form a base plane with $Y=0$. The selection of the 3D lowest points is carried out as follow: the 3D points are divided in sets following the $Z$ axis. In each set, we note $Y_{\max }$ and $Z_{\max }$ the maximum $Y$ and $Z$ coordinate of selected points, $Y_{\min }$ and $Z_{\min }$ the minimum $\mathrm{Y}$ and $Z$ coordinate of selected points. Then we estimate $\Delta_{y}=Y_{\max }-Y_{\min }$. Due to the possible inclination of the ground, two conditions are used to select the points of the ground: $Y \leq Y_{\min }+\Delta_{y}$ and $Z \leq Z_{\text {min }}+\Delta_{z}$. For each 3D set of fire points obtained at a given time, the $Y$ coordinate of the highest point corresponds to the flame length, $L$. This 
procedure is carried out for each image of the set of images acquired during the steady phase. From all the flame length values, the mean $\bar{L}$ and the standard deviation $\sigma_{L}$ are computed. Then, the values of $L$ that are within the interval $\left[\bar{L}-\sigma_{L}, \bar{L}+\sigma_{L}\right]$ are averaged in order to compute the estimated flame length of the whole steady phase.

\subsection{Measurement of fireline intensity by oxygen consumption calorimetry}

\subsubsection{Experimental device and basic equations}

Oxygen Consumption (OC) calorimetry is a common method used to measure the Heat Release Rate (HRR in kW). HRR which describes the fire size of burning materials is a fundamental parameter that is essential to estimate fire hazards [26]. It is then used to derive fireline intensity $(\mathrm{kW} / \mathrm{m})$. The oxygen consumption calorimetry principle is based on the assumption that the amount of heat released per unit mass of consumed oxygen is approximately constant for most common burning materials containing $\mathrm{C}, \mathrm{H}$ and $\mathrm{O}$ [27]. Thus, the heat release rate can be approximated by measuring the oxygen deficit in the exhaust gas flow of burning materials. HRR measurements based on OC calorimetry were conducted using a $1 \mathrm{MW}$ Large Scale Heat Release (LSHR) calorimeter $(3 \mathrm{~m} \times 3 \mathrm{~m}$ hood). Figure 6 shows the Open-burning HHR Calorimeter with a combustion bench inside. The HRR is given by the following relations

$$
\begin{gathered}
\dot{q}=\frac{E \rho_{0} W_{O_{2}}}{W_{\text {air }}}\left(1-X_{H_{2} O}^{\circ}\right) X_{O_{2}}^{a^{\circ}} \dot{V}_{s, 298}\left(\frac{\phi}{(1-\phi)+\alpha \phi}\right) \\
\dot{V}_{s, 298}=22.4 A \frac{k_{t}}{k_{p}} \sqrt{\frac{\Delta P}{T_{S}}} \\
\phi=\frac{X_{O_{2}}^{a^{\circ}}\left(1-X_{C O_{2}}^{a}\right)-X_{O_{2}}^{a}\left(1-X_{C O_{2}}^{a^{\circ}}\right)}{X_{O_{2}}^{a^{\circ}}\left(1-X_{C O_{2}}^{a}-X_{O_{2}}^{a}\right)}
\end{gathered}
$$

where $\dot{q}$ is the HRR, $E$ is Huggett's constant [27], $\rho_{0}$ is the density of dry air at $298 \mathrm{~K}$ and $1 \mathrm{~atm}, W_{O_{2}}$ is the molecular weight of oxygen, $W_{\text {air }}$ is the molecular weight of air, $X$ denotes the molar fraction, $\dot{V}_{s, 298}$ is the standard flow rate in the exhaust duct. Superscript ${ }^{\circ}$ is for incoming air, $a$ is for analyzers. $A$ is the cross sectional area of the duct, $k_{t}$ is a constant determined by calibration with a propane burner, $k_{p}=1.108$ for a bi-directional probe, $\Delta p$ is the pressure drop across the bi-directional probe and $T_{s}$ is the gas temperature in the duct. 


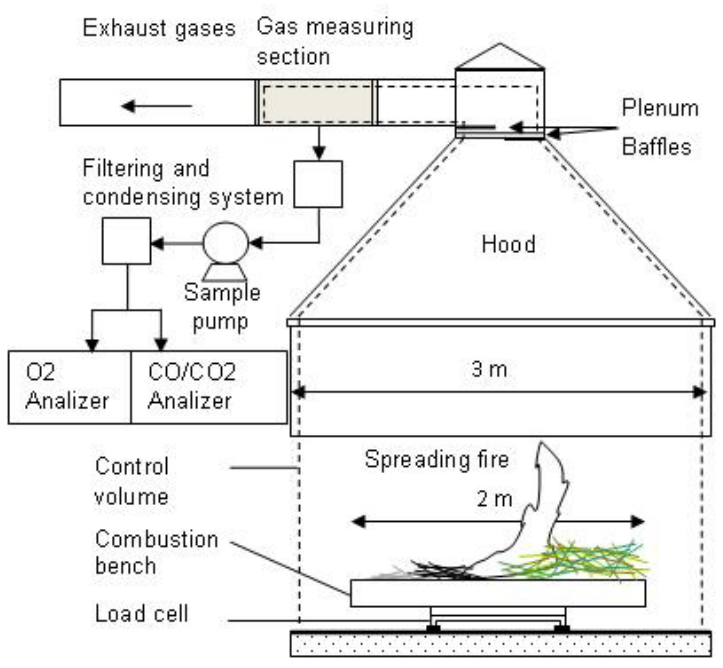

Figure 6: Large scale heat release calorimeter.

\subsubsection{Experimental procedure and fuel bed properties}

Three species of vegetation were considered: Pinuspinaster (PP) needles, Avenafatua (AF) straw (wild oats) and Genistasalzmannii (GS) spines (an endemic broom). Experimental fires were conducted under no slope and no wind for line-ignition fires (see Figure3). The fuels were scattered uniformly on the tray to obtain homogeneous beds. To ensure fast and linear ignition, a small amount of alcohol and a flame torch were used. The range of fuel bed properties for each vegetation species are provided in table 1 where $w, \delta, \rho, \sigma$ and $\beta$ represent respectively the fuel load, the depth of the fuel bed, the density of the particles, the surface to volume ratio of the particles and the packing ratio of the fuel bed. $\Delta H_{c, \text { net }}$ is the net heat of combustion.

The fire fronts remained quasi linear during the whole spreads and exhibited a weak curvature on the flanks when reaching the end of the combustion bench.

Table 1: $\quad$ Range of fuel bed properties of the vegetation species.

\begin{tabular}{|l|c|c|c|c|c|c|}
\hline Species & $\begin{array}{c}\Delta H_{c, \text { net }} \\
(\mathrm{kJ} / \mathrm{kg})\end{array}$ & $\begin{array}{c}\sigma \\
\left(\mathrm{m}^{-1}\right)\end{array}$ & $\begin{array}{c}\rho \\
\left(\mathrm{kg} / \mathrm{m}^{3}\right)\end{array}$ & $\begin{array}{c}p_{M} \\
(\%)\end{array}$ & $\begin{array}{c}w \\
\left(\mathrm{~kg} / \mathrm{m}^{2}\right)\end{array}$ & $\begin{array}{c}\delta \\
(\mathrm{cm})\end{array}$ \\
\hline Avena Fatua (AF) & 17091 & 2394 & 287 & $4-7$ & 0.6 & 7 \\
\hline $\begin{array}{l}\text { Genista salzmannii } \\
(\text { GS })\end{array}$ & 20645 & 3100 & 967 & 5 & 0.9 & 3.5 \\
\hline $\begin{array}{l}\text { Pinus pinaster } \\
(P P)\end{array}$ & 20411 & 3057 & 511 & $3-5$ & $0.6-1.2$ & $3-7$ \\
\hline
\end{tabular}


The fireline intensity obtained by $\mathrm{OC}$ calorimetry denoted $I_{O C}$, corresponds directly to the measured HRR for fire front of $1 \mathrm{~m}$ width. For fuel bed of smaller width $W$, the fireline intensity is given by:

$$
I_{O C}=\dot{q} / W
$$

\section{Results and discussion}

\subsection{Laboratory scale experiments}

\subsubsection{Geometrical characterization of the flame using stereovision}

The height of the flame is estimated from visible stereoscopic images without the need of position markers for deriving scale and orthogonality present in the images. Stereovision gives metric measurements and it is then possible to distinguish easily points that are on the ground from points located above (point number 4 in Figure 5 for example). The precision of the measurement using stereovision has been tested with a fire front model (with maximum dimensions: height: 0.9 ; width: 1.9 ; depth: $0.9 \mathrm{~m}$ ) which has been constructed from a metal frame and covered with red paper. Patterns have been added in order to have points of interest on the form that can be easily detected. The stereovision system was positioned at 4 meters of the model. The height of the estimated 3D pattern points and the maximum height of the model have been compared with the real one and the accuracy is about one millimetre.

\subsubsection{Fireline intensity measured by oxygen consumption calorimetry}

Figure 7 displays an example of a curve of fireline intensity for fire spreading across PP for a load of $1.2 \mathrm{~kg} / \mathrm{m}^{2}$. The corresponding mass loss over time is superimposed on the HRR curves.

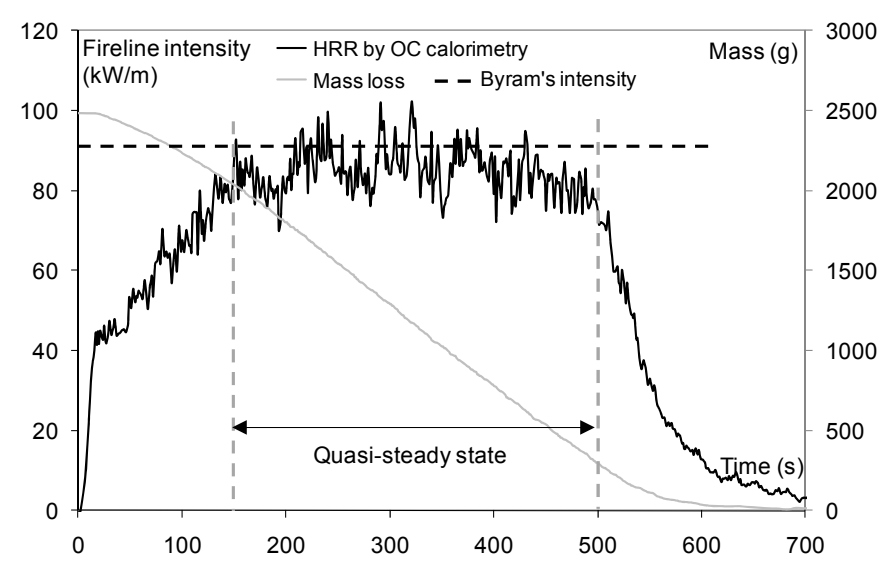

Figure 7: Fireline intensity and mass loss over time for fire spread across a fuel bed of PP for a load of $1.2 \mathrm{~kg} / \mathrm{m}^{2}$. 
Figure 8 shows OC calorimetry intensities versus Byram's intensities for the whole set of experiments conducted. We can see that Byram's formulation $I_{B}$, overestimates $I_{O C}$, the fireline intensity measured by $\mathrm{OC}$ calorimetry. The ratio between both formulations given by the linear regression is $I_{O C} / I_{B} \approx 0.84$.

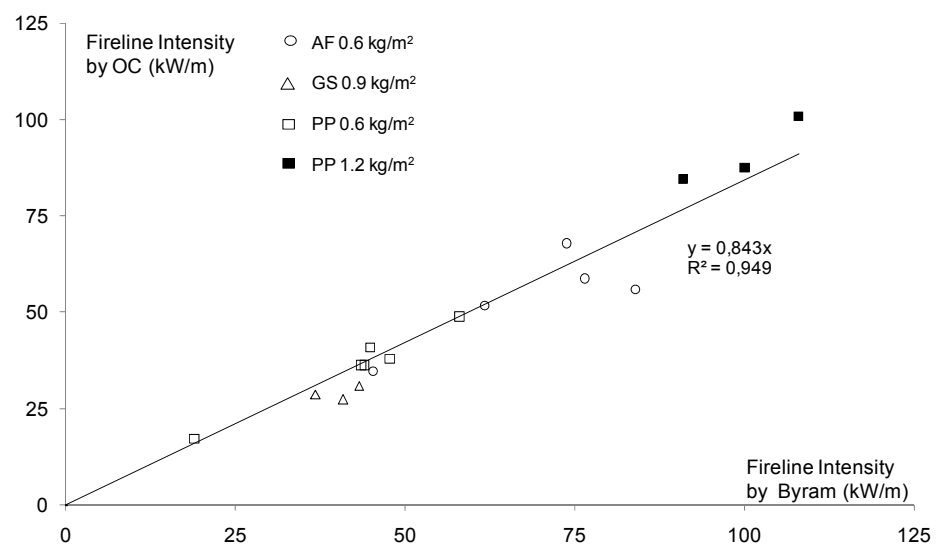

Figure 8: $\quad$ OC calorimetry Fireline intensity versus Byram’s intensity.

\subsubsection{Relationship between flame length and fireline intensity}

The predictions of current correlation of flame length vs fireline intensity are plotted in Figure 9. The circle represents the fireline intensities obtained with the calorimeter. The flame length was obtained by stereovision.

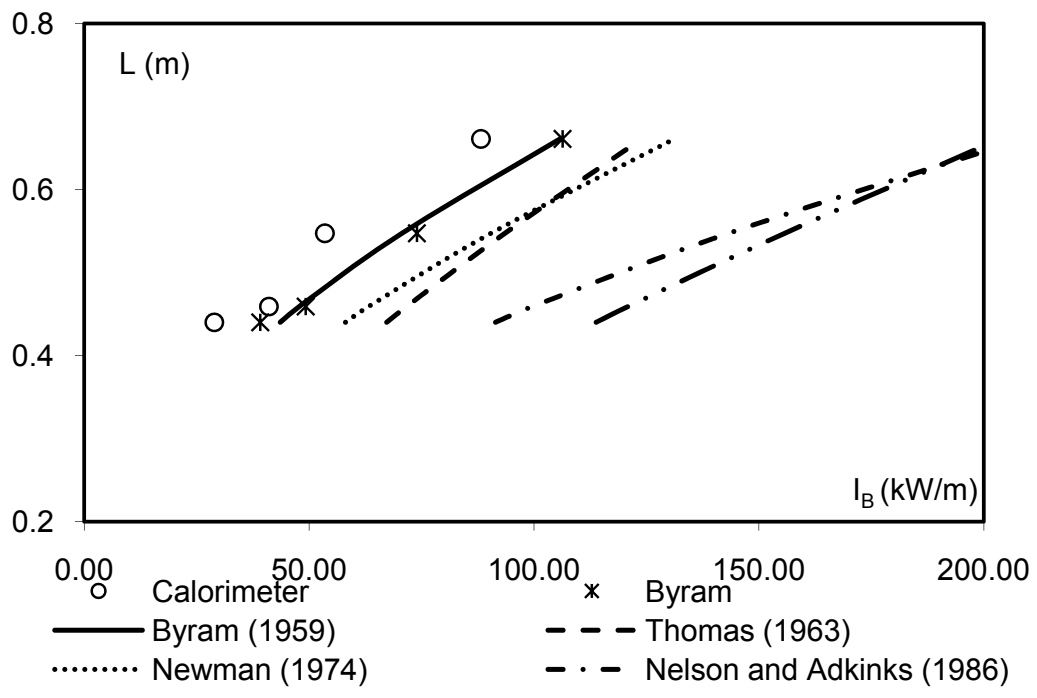

Figure 9: Flame length versus predicted fireline intensity, Byram's intensity and fireline intensity measured by OC. 
We observe that all the correlation models overestimate the fireline intensity measured by OC. It should be noticed that the Byram fireline intensity computed from the measured flame length with eqn. (2) matches the one computed using eqn. (1) denoted by marker $*$ in figure 9 , showing that the flame length is well measured. In order to take into account the good values (circle in figure 9) the new correlation between the intensity and the flame length is proposed as:

$$
\Leftrightarrow \mathrm{L}=0.0646 \mathrm{I}^{0.5281}
$$

\section{Conclusion}

Combined stereovision and oxygen consumption calorimetry allowed establishing a new correlation to assess fireline intensity. This first step is promising. In future, this correlation will be tested at field scale and the link between geometrical flame properties and radiant heat flux ahead of a fire front will be investigated.

\section{Acknowledgements}

This work was carried out in the scope of project PROTERINA-C supported by the EU under the Thematic 3 of the Operational Program Italia/France Maritime 2007-2013, contract: G25I08000120007.

\section{References}

[1] Byram G.M., Combustion of forest fuels (Chapter 3). Forest fire: control and use, ed. K.P. Davis, McGraw-Hill: New York, pp. 61-89, 1959.

[2] Fites J.A. \& Henson C., Real-time evaluation of effects of fuel-treatments and other previous land management activities on fire behavior during wildfires, Report of the Joint fires science rapid response project, US Forest Service, pp. 1-13, 2004.

[3] McAthur A.G., Communication, 1962, Control burning in eucalypt forests, Forestry and Timber Bureau Leaflet, Australia, No 80.

[4] Hammil K.A. \& Bradstock R.A., Remote sensing of fire severity in Blue Mountains: influence of vegetation type and inferring fire intensity. International Journal of Wildland Fire, 15, pp.213-226, 2006.

[5] Palheiro P.M., Fernandes P. \& Cruz M.G., A fire behaviour-based fire danger classification for maritime pine stands: comparison of two approaches. Proc. of the $V^{\text {th }}$ International Conference on Forest Fire Research, ed. D.X. Viegas, CD-ROM, 2006.

[6] Albini F.A., Wildland fires, American Scientist, 72, pp.590-597, 1984.

[7] Newman M., Toward a common language for aerial delivery mechanics. Fire Management Notes, 35, pp. 18-19, 1974.

[8] Thomas H., The size of flames from natural fire. In: proceedings of the $9^{\text {th }}$ symposium on combustion. Proc. of the combustion Institute, Pittsburgh, pp. 844-859, 1963. 
[9] Nelson R.M. Jr. \& Adkins C.A., Flame characteristics of wind-driven surfaces fires. Canadian Journal of Forest Research, 16, pp. 1293-1300, 1986.

[10] Weise D.R. \& Biging G.S., Effects of wind velocity and slope on flame properties. Canadian Journal of Forest Research, 26, pp. 1849-1858, 1996.

[11] Martinez-de Dios J. R., André J. C., Gonçalves J. C., Arrue B. Ch., Ollero A. and Viegas D. X. Laboratory Fire Spread Analysis Using Visual and Infrared Cameras Inter. Journ. of Wildland Fire15, pp. 175-86, 2006.

[12] Adkins C.W., Fire image Analysis System version 5.0. Proc of the 12th Conference on fire and meteo, Jekill Island, Georgie. Poster, 1993.

[13] Hartley, R., Zissermann, A., Multiple view geometry in computer vision, Cambridge university press, 2nd Edition, 2003.

[14] Ayache, N, Sander, P.T., Artificial Vision for Mobile Robots: Stereo Vision and Multisensory Perception, MIT Press, 1991.

[15] Zhang, Z., Determining the Epipolar Geometry and its Uncertainty: A Review, International Journal of Computer Vision, 27(2), pp.161-198, 1998.

[16] Hartley, R., Stereo from uncalibrated cameras, Proc. of the Second Joint European - US Workshop on Applications of Invariance in Computer Vision, pp. 237-256, 1994.

[17] Trucco, E., Verri, A., Introductory Techniques for 3-D Computer Vision, Prentice Hall, 1998.

[18] C. Harris, M. Stephens, A combined corner and edge detector, Proc of the 4th Alvey Vision Conf, pp. 189-192, 1998.

[19] Gonzales, R. C., Woods R. E., Eddins S. L., Digital Image processing using Matlab, Pearson prentice Hall, pp. 237-240, 2004.

[20] Horaud R., Monga O., Vision par ordinateur, Outils fondamentaux, Hermes Science Publication, 2nd Edition, 1995.

[21] He H.C. and Yung N.H.C., A corner detector based on global and local curvature properties, Optical Engineering; 47(5), pp. 057008-1 - 057008$12,2008$.

[22] http://www.ptgrey.com/products/bbxb3/index.asp

[23] Bumblebee XB3 Getting Started Manual http://www.ptgrey.com/support /downloads/documents/Bumblebee\%20XB3\%20Getting\%20Started\%20Ma nual.pdf

[24] L. Rossi, T. Molinier, M. Akhloufi, Y. Tison and A. Pieri, A 3D vision system for the measurement of the rate of spread and the height of fire fronts, Meas. Sci. Technol. 21(10) 12p, doi:10.1088/09570233/21/10/105501, 2010.

[25] B.C. Ko, K.H. Cheong, J.Y. Nam, Fire detection based on vision sensor and support vector machines, Fire Safety Journal 44, pp. 322-329, 2009.

[26] V. Babrauskas \& R.D. Peacock, Heat release rate: The single most important variable in fire hazard. Fire Safety Journal, 18, pp. 255-292, 1992.

[27] C. Huggett, Estimation of the rate of heat release by means of oxygen consumption. Journal of Fire and Flammability, 12, pp. 61-65, 1980. 